\title{
Midfacial soft tissue changes after maxillary expansion using micro-implant-supported maxillary skeletal expanders in young adults: A retrospective study
}

\author{
Hieu Nguyen ${ }^{\mathrm{a}}$ (1) \\ Jeong Won Shin ${ }^{\mathrm{a}}$ (1) \\ Hai-Van Giap ${ }^{a}$ \\ Ki Beom Kim ${ }^{\mathrm{b}}$ \\ Hwa Sung Chae ${ }^{\mathrm{a}}$ \\ Young Ho Kim \\ Hae Won Choi ${ }^{\mathrm{C}}$ (1)
}

${ }^{a}$ Department of Orthodontics, Institute of Oral Health Science, Ajou University School of Medicine, Suwon, Korea

${ }^{\mathrm{b}}$ Department of Orthodontics, Center for Advanced Dental Education, Saint Louis University, Saint Louis, MO, USA

'Department of Orthodontics,

The Institute of Oral Health

Science, Samsung Medical Center,

Sungkyunkwan University School of

Medicine, Seoul, Korea

\begin{abstract}
Objective: The aim of this retrospective study was to assess the midfacial soft tissue changes following maxillary expansion using micro-implantsupported maxillary skeletal expanders (MSEs) in young adults by cone-beam computerized tomography (CBCT) and to evaluate the correlations between hard and soft tissue changes after MSE usage. Methods: Twenty patients (mean age, 22.4 years; range, 17.6-27.1) with maxillary transverse deficiency treated with MSEs were selected. Mean expansion amount was $6.5 \mathrm{~mm}$. CBCT images taken before and after expansion were superimposed to measure the changes in soft and hard tissue landmarks. Statistical analyses were performed using paired $t$-test and Pearson's correlation analysis on the basis of the normality of data. Results: Average lateral movement of the cheek points was $1.35 \mathrm{~mm}$ (right) and $1.08 \mathrm{~mm}$ (left), and that of the alar curvature points was $1.03 \mathrm{~mm}$ (right) and $1.02 \mathrm{~mm}$ (left). Average forward displacement of the cheek points was 0.59 $\mathrm{mm}$ (right) and $0.44 \mathrm{~mm}$ (left), and that of the alar curvature points was 0.61 $\mathrm{mm}$ (right) and $0.77 \mathrm{~mm}$ (left) $(p<0.05)$. Anterior nasal spine (ANS), posterior nasal spine (PNS), and alveolar bone width showed significant increments $(p<$ 0.05). Changes in the cheek and alar curvature points on both sides significantly correlated with hard tissue changes $(p<0.05)$. Conclusions: Maxillary expansion using MSEs resulted in significant lateral and forward movements of the soft tissues of cheek and alar curvature points on both sides in young adults and correlated with the maxillary suture opening at the ANS and PNS.
\end{abstract}

[Korean J Orthod 2021;51(3):145-156]

Key words: Maxillary expansion, Micro-implant-supported maxillary skeletal expander, Soft tissue change

Received July 2, 2020; Revised September 13, 2020; Accepted November 16, 2020.

Corresponding author: Hae Won Choi.

Clinical Associate Professor, Department of Orthodontics, The Institute of Oral Health Science, Samsung Medical Center, Sungkyunkwan University School of Medicine, 81 Irwon-ro, Gangnam-gu, Seoul 06351, Korea.

Tel+82-2-3410-2420 e-mail orthochoi7@gmail.com

Hieu Nguyen and Jeong Won Shin contributed equally to this work (as co-first authors).

How to cite this article: Nguyen H, Shin JW, Giap HV, Kim KB, Chae HS, Kim YH, Choi HW. Midfacial soft tissue changes after maxillary expansion using micro-implantsupported maxillary skeletal expanders in young adults: A retrospective study. Korean J Orthod 2021;51:145-156.

(C) 2021 The Korean Association of Orthodontists.

This is an Open Access article distributed under the terms of the Creative Commons Attribution Non-Commercial License (http://creativecommons.org/licenses/by-nc/4.0) which permits unrestricted non-commercial use, distribution, and reproduction in any medium, provided the original work is properly cited. 


\section{INTRODUCTION}

Maxillary transverse deficiency is one of the skeletal problems in the craniofacial region encountered during orthodontic treatment.' ${ }^{1}$ To correct this malocclusion, rapid maxillary expansion (RME) treatments have been used for more than a century. ${ }^{2,3}$ Several studies have proven that RME increases the arch width and perimeter to allow correction of posterior crossbite and to provide space for alleviation of crowding of the dentition. ${ }^{4,5}$ However, limited skeletal movement, dentoalveolar tipping, root resorption, detrimental periodontal consequences, and lack of long-term stability have been reported as the undesirable adverse effects of this procedure. $^{6}$

With the widespread use of temporary anchorage devices, the micro-implant-supported maxillary skeletal expander (MSE) was recently developed to open the midpalatal suture and achieve skeletal expansion. ${ }^{7-9}$ Numerous positive results pertaining to the skeletal effects of MSEs have been reported in different studies., ${ }^{70}$ However, limited data have been published regarding soft tissue changes and their correlation with hard tissue changes in young adult patients. ${ }^{11,12}$

Three-dimensional (3D) soft tissue analysis using the 3dMD Face system (3dMD, Atlanta, GA, USA) after expansion with MSEs showed significant changes in the paranasal region, upper lip, and both cheeks." In contrast, another study that performed stereophotogrammetric analysis reported that the effect of RME appliances on nasolabial soft tissues in growing patients could be considered as clinically non-significant. ${ }^{13}$ Conebeam computerized tomography (CBCT) is a useful 3D imaging method for accurate evaluation of hard and soft tissue changes. ${ }^{14}$ Moreover, advancements in software development have allowed improved manipulation and visualization of CBCT images, facilitating collection of reliable and precise information. ${ }^{15}$

Thus, the aim of this study was to assess the midfacial soft tissue changes induced by MSE use in young adults by CBCT, and to evaluate the correlations between hard and soft tissue changes.

\section{MATERIALS AND METHODS}

This retrospective study analyzed the CBCT images of patients who received orthodontic treatment for the resolution of maxillary transverse deficiency at Samsung Medical Center and was approved by the Institutional Review Board (IRB) (approval No. SMC MD IRB 2019-09127-001). Due to the retrospective nature of this study, the Committee waived the need for signed informed consent.

A total of 20 patients ( 12 men, 8 women) with a mean age of 22.4 years (range, 17.6-27.1 years) whose skeletal growth had stopped were selected. СBCT images before the delivery of the MSE (T0) and post-expansion (T1) were obtained. The mean treatment duration was 48.5 days (range, 31-80 days), and the mean amount of expansion was $6.5 \mathrm{~mm}$ (range, $5.2-8.0 \mathrm{~mm}$ ). The postexpansion CBCT images were acquired within 4 weeks (mean duration, 21 days; range, 1-28 days) of completion of expansion. The mean interval between pre- and post-expansion CBCT images was 76.5 days (range, 42-108 days).

The inclusion criteria were as follows: transverse maxillary deficiency of more than $5 \mathrm{~mm}^{16}$; absence of any previous midfacial trauma; absence of functional shift; and no history of previous orthodontic treatment. We excluded the following patients: patients with systemic diseases or syndromes; growth; severe facial asymmetry; and no separation of the midpalatal suture.

The MSE type 11 device (BioMaterials Korea Inc., Seoul, Korea) is a specific type of bone-borne expander that uses four micro-implants in the posterior area of the palate with bicortical engagement, with an 8-mm expansion jackscrew unit supported by the four palatal micro-implants with diameters of $1.8 \mathrm{~mm}$ and lengths of $11 \mathrm{~mm}$ attached to the first molars with connecting arms and molar bands. ${ }^{10}$ The rate of expansion was two turns per day (0.13 mm per turn) until diastema appeared, after which the rate was reduced to one turn per day to minimize periodontal side effects. The expansion was stopped when the required amount of expansion to correct the maxillo-mandibular transverse discrepancy was achieved ${ }^{16}$ and $20 \%$ overexpansion was performed ${ }^{17}$ (Figure 1). After completion, the MSE was retained for at least 3 months for stabilization.

All CBCT images were taken by the same technician using a CBCT scanner (CS 9300; Carestream Dental, Atlanta, GA, USA) with image resolution up to $90 \mu \mathrm{m}$, exposure parameters of $90 \mathrm{kV}$ and $4 \mathrm{~mA}, 300-\mu \mathrm{m}$ voxel size, and volume dimensions of $17 \times 13.5 \mathrm{~cm}^{2}$. During image acquisition, the patients were seated in a vertical position, with the Frankfort horizontal plane parallel to the floor and the patient's head stabilized by an ear rod. The images were imported as digital imaging and communications in medicine (DICOM) files using OnDemand3D software (CyberMed Inc, Seoul, Korea). Using the anatomical structures of the anterior cranial base, superimposition of the post-expansion CBCT images onto the pre-expansion СВСТ images was performed, as proposed by Cevidanes et al. (Figure 2). ${ }^{18,19}$ The superimposition method used the voxel grayscale and was fully automated by the "Automatic Registration" tool of the software to avoid operator-related errors (Figure 3), a procedure whose accuracy has been previously validated. ${ }^{19}$ 

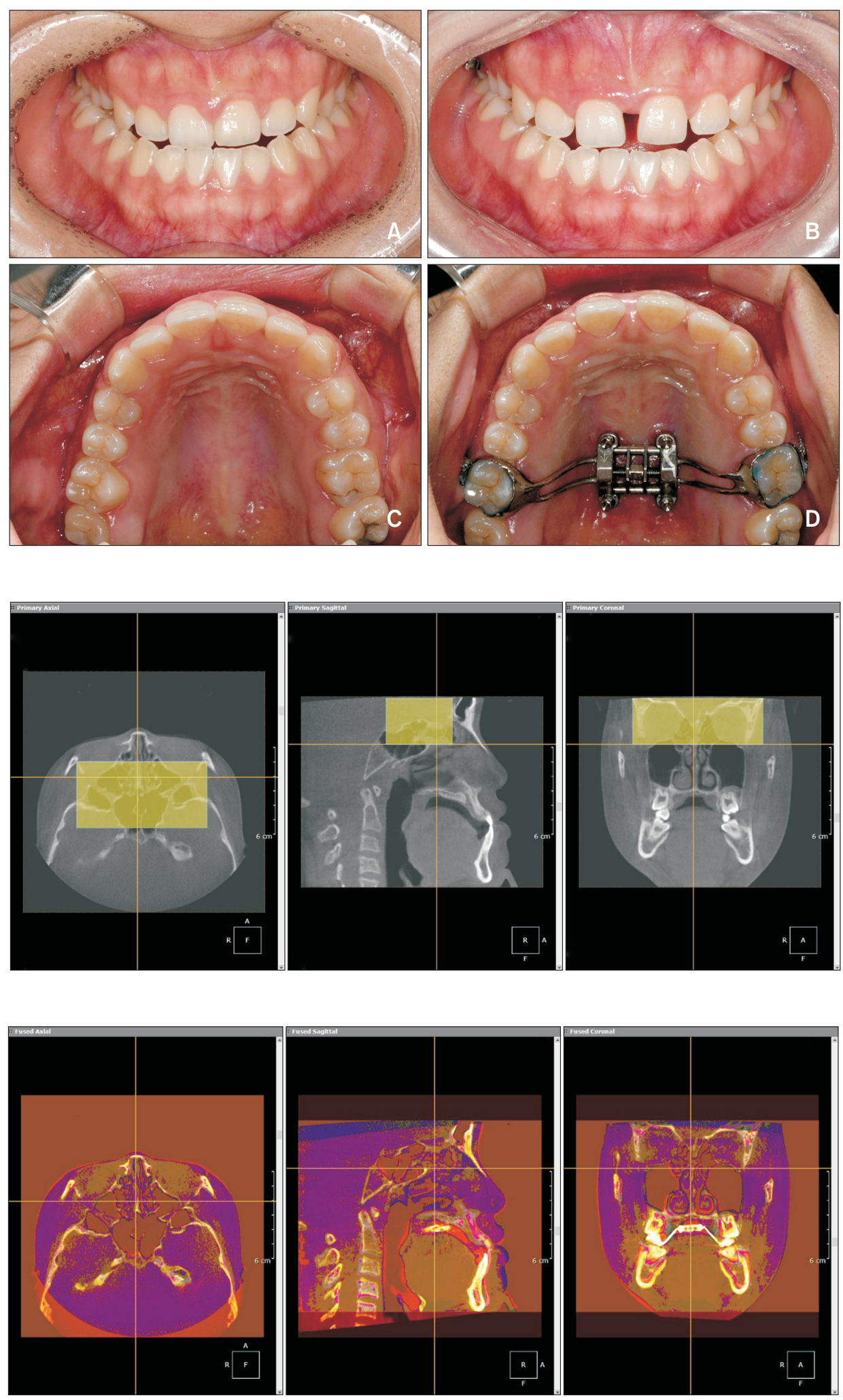

Figure 3. Superimposed preand post-expansion conebeam computerized tomography (CBCT) scans following maxillary skeletal expander use (primary CBCT, violet; secondary $\mathrm{CBCT}$, red).

Figure 1. Intraoral photographs of a maxillary skeletal expander (MSE). A, C, Before activation of the MSE. B, Diastema following MSE use. D, After activation of the MSE.

Figure 2. OnDemand 3D (CyberMed Inc, Seoul, Korea) voxel-based superimposition on the cranial base. The yellow box was used to determine the area of the cranial base which was the reference for superimposition.

the anteroposterior axis, was perpendicular to the Or line and parallel to the right Frankfort horizontal ( $\mathrm{R} \mathrm{FH}$ ) line. The $\mathrm{z}$-axis, the vertical axis, was perpendicular to both the Or and R FH lines (Figure 4). Assuming the pa-
The coordinate system featured three axes ( $\mathrm{x}, \mathrm{y}$, and $\mathrm{z})$ with the origin $(0,0,0)$ registered at nasion $(N)$. The $x-$ axis, the transverse axis, was parallel to the orbitale (Or) line passing through the left and right Or. The $y$-axis, 


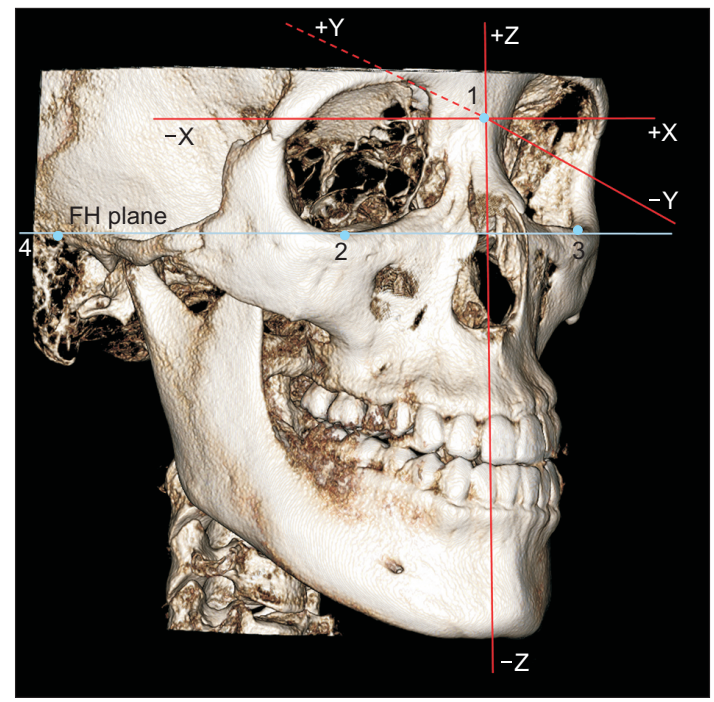

Figure 4. The coordinate system consists of three axes $(x$, $y, z)$ with their origin $(0,0,0)$ registered at nasion. 1, nasion; 2 and 3, orbitale (right and left); 4, porion (right). Positive values are to the left, posterior, and superior to the nasion point.

$\mathrm{FH}$, Frankfort horizontal. tient was in an anatomical position, positive values were to the left, posterior, and superior to the $\mathrm{N}$ point of the patient (Figure 4), and negative values were to the right, anterior, and inferior to the $\mathrm{N}$ point. The 3D coordinates $(\mathrm{x}, \mathrm{y}, \mathrm{z})$ of any landmark represented its 3D position relative to $\mathrm{N}(0,0,0)$.

In the OnDemand3D software, landmark points were defined using the $(x, y, z)$ Cartesian coordinate system based on the three orientation planes. A series of 19 points were marked on each pre- and post-expansion CBCT scan. On each scan, three points (subnasale, soft tissue A point, and labial superius) with three pairs of soft tissue landmarks (cheilion, cheek point, and the alar curvature point on both sides), and five pairs of hard tissue landmarks (A point, prosthion, ectocanine, ectomolare, and processus zygomaticus on both sides) were identified on the basis of previous reports (Table 1, Figures 5 and 6). ${ }^{14}$ The 3D changes in their position between $\mathrm{T} 0$ and $\mathrm{T} 1$ were defined as the differences in their three coordinates. To investigate the amount of skeletal expansion, the following parameters were evaluated: amount of expansion at the anterior nasal spine (ANS) and posterior nasal spine (PNS), ${ }^{20}$ and alveolar width (Table 1, Figure 7). ${ }^{21}$

Table 1. Definitions of the landmarks and parameters used in this study

\begin{tabular}{|c|c|c|}
\hline & Landmark & Description \\
\hline \multirow[t]{6}{*}{ Soft tissue } & Subnasale & $\begin{array}{l}\text { The midpoint on the nasolabial soft tissue contour between the columella crest and } \\
\text { upper lip }\end{array}$ \\
\hline & Alar curvature point & The point located at the facial insertion of the alar base \\
\hline & Soft tissue A point & The most posterior midpoint of the philtrum \\
\hline & Labrale superius & The midpoint of the vermilion line of the upper lip \\
\hline & Cheilion & The point located at each labial commissure \\
\hline & Cheek point & The point located at the center of the cheek area \\
\hline \multirow[t]{5}{*}{ Hard tissue } & A point & $\begin{array}{l}\text { The most posterior and deepest point on the anterior contour of the maxillary alveolar } \\
\text { process }\end{array}$ \\
\hline & Prosthion & $\begin{array}{l}\text { The most anteroinferior point on the maxillary alveolar margin in the mid-sagittal } \\
\text { plane }\end{array}$ \\
\hline & Ectocanine & $\begin{array}{l}\text { The most inferolateral point on the alveolar ridge opposite the center of the maxillary } \\
\text { canine }\end{array}$ \\
\hline & Ectomolare & $\begin{array}{l}\text { The most inferolateral point on the alveolar ridge opposite the center of the maxillary } \\
\text { first molar }\end{array}$ \\
\hline & Processus zygomaticus & The most inferolateral point of the processus zygomaticus \\
\hline \multirow[t]{3}{*}{ Parameter } & ANS width & $\begin{array}{l}\text { Distance between the R and L halves of the ANS in the axial section passing through } \\
\text { the ANS }\end{array}$ \\
\hline & PNS width & $\begin{array}{l}\text { Distance between the } \mathrm{R} \text { and } \mathrm{L} \text { halves of the PNS in the axial section passing through } \\
\text { the PNS }\end{array}$ \\
\hline & Alveolar width & $\begin{array}{l}\text { Distance between the R and } \mathrm{L} \text { buccal alveolar bones on a line connecting the } \mathrm{R} \text { and } \mathrm{L} \\
\mathrm{M} 1 \text { furcations in the coronal section passing through the Ml furcations }\end{array}$ \\
\hline
\end{tabular}

ANS, anterior nasal spine; PNS, posterior nasal spine; R, right; L, left; M1, maxillary first molar. 


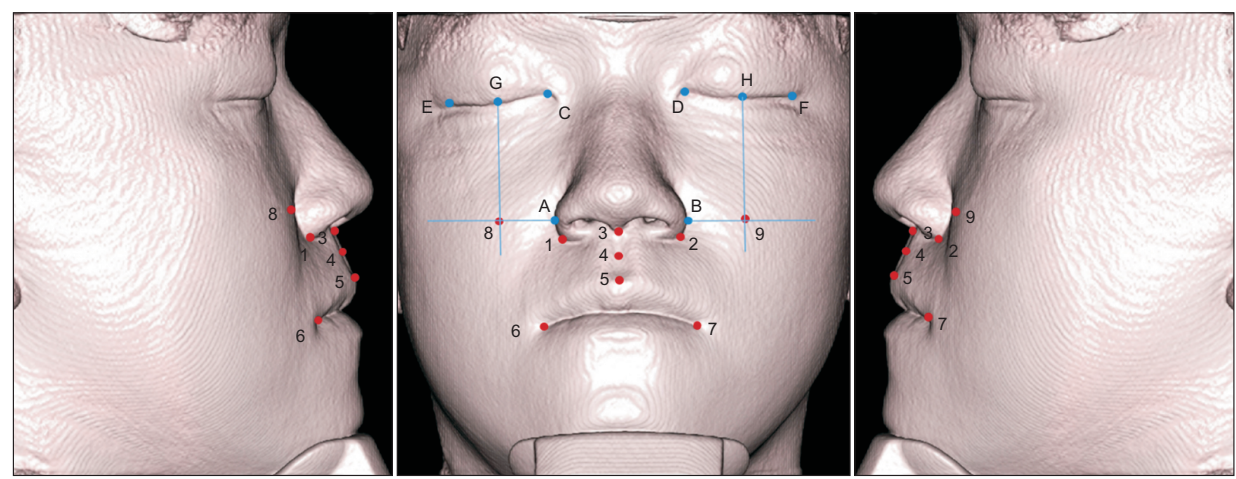

Figure 5. Soft tissue landmarks used in this study. 1 and 2, alar curvature points (right and left); 3, subnasale; 4, soft tissue A point; 5, labrale superius; 6 and 7, cheilion (right and left); 8 and 9, cheek points (right and left; the intersection point of the vertical and horizontal blue lines. The vertical blue line passes through the mid-canthus parallel to the zaxis. The horizontal blue line is perpendicular to the vertical line passing through the alare); $A$ and $B$, alare (right and left; the most lateral point on each alar contour); $C$ and $D$, endocanthus (right and left); $E$ and $F$, exocanthus (right and left); $\mathrm{G}$ and $\mathrm{H}$, mid-canthus (right and left).
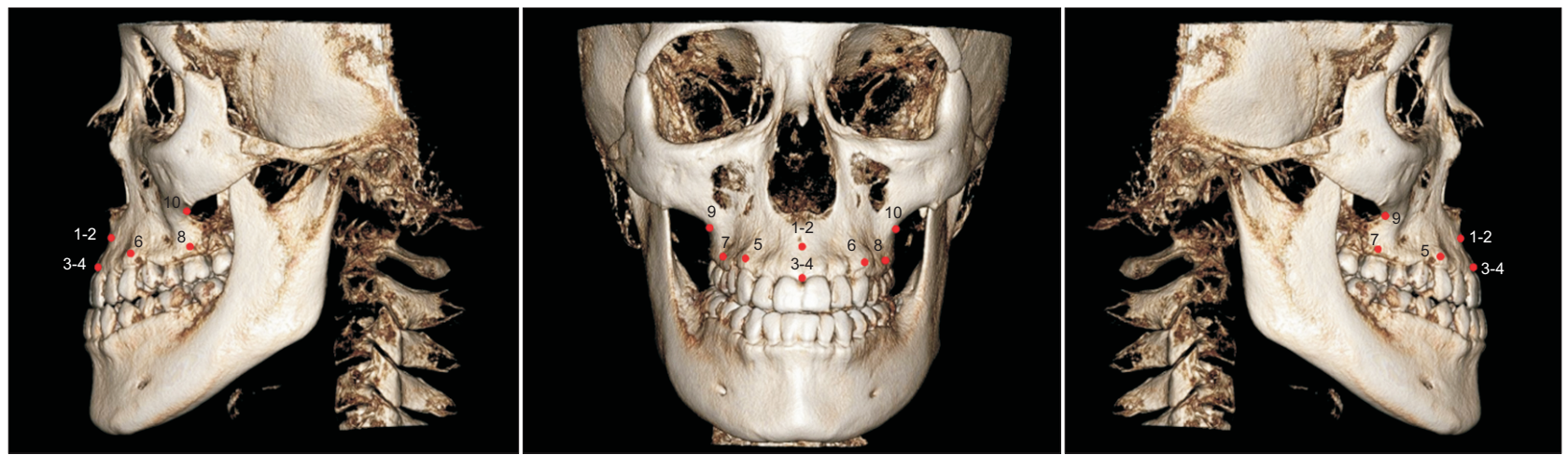

Figure 6. Hard tissue landmarks used in this study. 1 and 2, A point (right and left); 3 and 4, prosthion (right and left); 5 and 6, ectocanine (right and left); 7 and 8, ectomolare (right and left); and 9 and 10, processus zygomaticus (right and left).
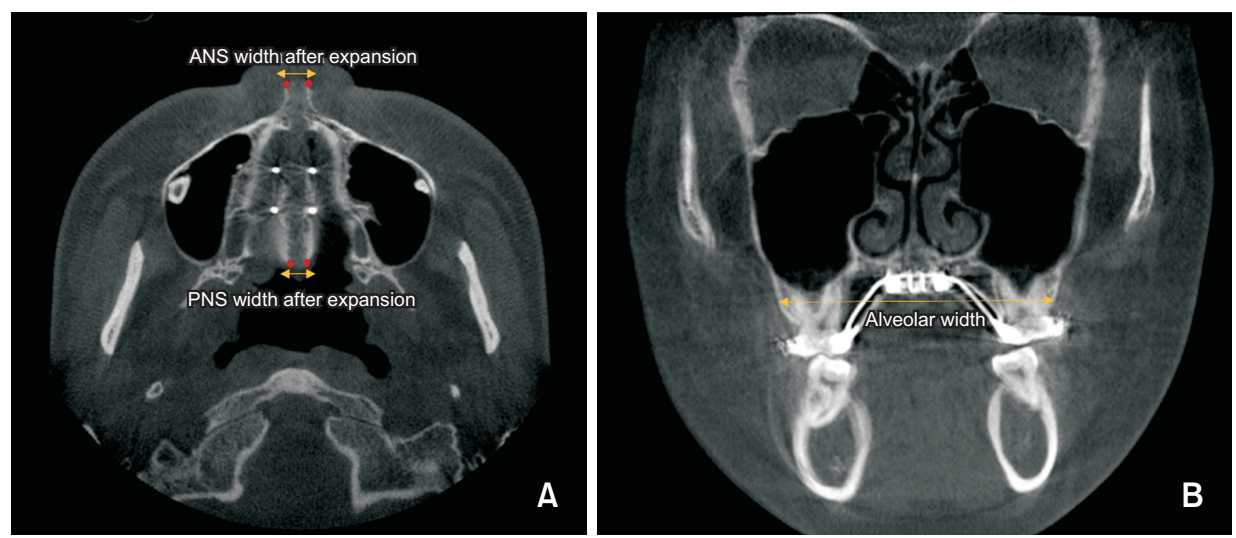

Figure 7. A, Anterior nasal spine (ANS) and posterior nasal spine (PNS) width after expansion. B, Alveolar width after expansion.

\section{Statistical analysis}

For sample size calculation, 17 data pairs achieved $80 \%$ power to reject the null hypothesis of zero effect size when the population effect size was 0.68 and the significance level was 0.05 using a two-sided paired $t$ test. The normality of data was determined using the 
Shapiro-Wilk test. Comparison of the coordinates of the soft tissue landmarks and hard tissue changes before and after expansion was performed using paired t-tests, based on the normality of data distribution. Pearson's correlation analysis was used to assess the correlation between hard and soft tissue changes. $p$-values $<0.05$ were considered statistically significant. All statistical analyses were performed using SPSS software, version 23 (IBM Corp., Armonk, NY, USA).

A single examiner performed all measurements. In order to determine the intraexaminer reliability, the same examiner reanalyzed 10 randomly selected patients within a 2-week interval. The resultant intraclass correlation coefficient (ICC) indicated high reliability (ICC > 0.90).
Cronbach's alpha was used to evaluate the reliability of the measurements, and was equal to 0.92, showing appropriate superimposition and measurement agreement.

\section{RESULTS}

In this study, the cheek points on the right and left sides moved laterally by $1.35 \mathrm{~mm}$ and $1.08 \mathrm{~mm}$ respectively, with statistical significance ( $p<0.001$; Table 2), and forward by $0.59 \mathrm{~mm}$ and $0.44 \mathrm{~mm}$ respectively, with statistical significance ( $p<0.05$; Table 2$)$. The alar curvature points on the right and left side moved laterally by $1.03 \mathrm{~mm}$ and $1.02 \mathrm{~mm}$, and forward by $0.61 \mathrm{~mm}$ and $0.77 \mathrm{~mm}$, respectively and the subnasale point moved

Table 2. Changes in soft tissue landmarks in the maxilla, assessed in the transverse (x), sagittal (y), and vertical (z) planes, after expansion $(\mathrm{mm})$

\begin{tabular}{|c|c|c|c|c|}
\hline Landmark & & $\Delta$ Coordinate & $\begin{array}{c}\text { Mean } \pm \text { standard } \\
\text { deviation }(\mathrm{mm})\end{array}$ & $p$-value \\
\hline \multirow[t]{3}{*}{ Subnasale } & & $\Delta \mathrm{x}$ & $-0.07 \pm 0.68$ & 0.631 \\
\hline & & $\Delta \mathrm{y}$ & $-0.23 \pm 0.56$ & 0.087 \\
\hline & & $\Delta \mathrm{z}$ & $-0.34 \pm 0.36$ & $0.000^{*}$ \\
\hline \multirow[t]{3}{*}{ Soft tissue A point } & & $\Delta \mathrm{x}$ & $-0.18 \pm 0.68$ & 0.249 \\
\hline & & $\Delta \mathrm{y}$ & $-0.35 \pm 1.07$ & 0.159 \\
\hline & & $\Delta \mathrm{z}$ & $-0.59 \pm 1.37$ & 0.067 \\
\hline \multirow[t]{3}{*}{ Labiale superius } & & $\Delta \mathrm{x}$ & $-0.19 \pm 0.82$ & 0.311 \\
\hline & & $\Delta \mathrm{y}$ & $-0.13 \pm 1.16$ & 0.624 \\
\hline & & $\Delta \mathrm{z}$ & $-0.30 \pm 0.92$ & 0.166 \\
\hline \multirow[t]{6}{*}{ Cheilion } & Right & $\Delta \mathrm{x}$ & $-0.41 \pm 1.39$ & 0.073 \\
\hline & & $\Delta \mathrm{y}$ & $-0.03 \pm 1.77$ & 0.941 \\
\hline & & $\Delta \mathrm{z}$ & $0.27 \pm 1.42$ & 0.400 \\
\hline & Left & $\Delta \mathrm{x}$ & $0.22 \pm 1.80$ & 0.586 \\
\hline & & $\Delta \mathrm{y}$ & $-0.38 \pm 1.82$ & 0.362 \\
\hline & & $\Delta \mathrm{z}$ & $0.29 \pm 1.48$ & 0.389 \\
\hline \multirow[t]{6}{*}{ Cheek point } & Right & $\Delta \mathrm{x}$ & $-1.35 \pm 0.31$ & $0.000^{*}$ \\
\hline & & $\Delta \mathrm{y}$ & $-0.59 \pm 0.60$ & $0.000^{*}$ \\
\hline & & $\Delta \mathrm{z}$ & $-0.53 \pm 1.29$ & 0.080 \\
\hline & Left & $\Delta \mathrm{x}$ & $1.08 \pm 0.28$ & $0.000^{*}$ \\
\hline & & $\Delta \mathrm{y}$ & $-0.44 \pm 0.75$ & $0.016^{*}$ \\
\hline & & $\Delta \mathrm{z}$ & $-0.55 \pm 1.30$ & 0.072 \\
\hline \multirow[t]{6}{*}{ Alar curvature point } & Right & $\Delta \mathrm{x}$ & $-1.03 \pm 0.68$ & $0.000^{*}$ \\
\hline & & $\Delta \mathrm{y}$ & $-0.61 \pm 0.54$ & $0.000^{*}$ \\
\hline & & $\Delta \mathrm{z}$ & $-0.27 \pm 1.00$ & 0.242 \\
\hline & Left & $\Delta \mathrm{x}$ & $1.02 \pm 0.62$ & $0.000^{*}$ \\
\hline & & $\Delta \mathrm{y}$ & $-0.77 \pm 0.67$ & $0.000^{*}$ \\
\hline & & $\Delta \mathrm{z}$ & $-0.25 \pm 0.94$ & 0.240 \\
\hline
\end{tabular}

Paired $t$-tests were performed; *Statistical significance with $p<0.05$. 
downward by $0.34 \mathrm{~mm}(p<0.001$; Table 2).

Based on the superimposition of the 3D skull models, all the investigated hard tissue landmarks showed significant lateral movement $(p<0.001$; Table 3$)$. Furthermore, the A point, ectocanine, and prosthion of each half of the maxilla shifted forward $(p<0.05$; Table 3$)$, whereas the A point moved downward by $0.30 \mathrm{~mm}$ on the right side and by $0.35 \mathrm{~mm}$ on the left side $(p<0.05$; Table 3).

Regarding the midpalatal suture, the splits at the ANS
$(4.83 \mathrm{~mm})$ and PNS $(3.95 \mathrm{~mm})$ were statistically significant ( $p<0.001$; Table 4), and the amount of PNS split corresponded to $81.78 \%$ of that of the ANS. Additionally, at the furcation of the maxillary first molars, the alveolar bone width after treatment showed a statistically significant increase of $4.19 \mathrm{~mm}(p<0.001$; Table 4).

Table 5 shows that while the changes in the $x$-coordinates of the cheek and alar curvature points on the left side were positively affected by the changes in the ANS and PNS, those on the right side were negatively

Table 3. Changes in hard tissue landmarks in the maxilla, assessed in the transverse $(\mathrm{x})$, sagittal $(\mathrm{y})$, and vertical (z) planes, after expansion ( $\mathrm{mm}$ )

\begin{tabular}{|c|c|c|c|c|}
\hline Landmark & & $\Delta$ Coordinate & $\begin{array}{c}\text { Mean } \pm \text { standard } \\
\text { deviation }(\mathbf{m m})\end{array}$ & $p$-value \\
\hline \multirow[t]{6}{*}{ A point } & To the right side & $\Delta \mathrm{x}$ & $-2.24 \pm 0.64$ & $0.000^{*}$ \\
\hline & & $\Delta \mathrm{y}$ & $-0.57 \pm 0.58$ & $0.000^{*}$ \\
\hline & & $\Delta \mathrm{z}$ & $-0.30 \pm 0.54$ & $0.023^{*}$ \\
\hline & To the left side & $\Delta \mathrm{x}$ & $2.21 \pm 0.97$ & $0.000^{*}$ \\
\hline & & $\Delta \mathrm{y}$ & $-0.55 \pm 0.51$ & $0.000^{*}$ \\
\hline & & $\Delta \mathrm{z}$ & $-0.35 \pm 0.57$ & $0.013^{*}$ \\
\hline \multirow[t]{6}{*}{ Prosthion } & To the right side & $\Delta \mathrm{x}$ & $-2.56 \pm 1.01$ & $0.000^{*}$ \\
\hline & & $\Delta \mathrm{y}$ & $-0.58 \pm 0.71$ & $0.002^{*}$ \\
\hline & & $\Delta \mathrm{z}$ & $-0.49 \pm 0.66$ & $0.003^{*}$ \\
\hline & To the left side & $\Delta \mathrm{x}$ & $2.47 \pm 0.94$ & $0.000^{*}$ \\
\hline & & $\Delta \mathrm{y}$ & $-0.55 \pm 1.05$ & $0.030^{*}$ \\
\hline & & $\Delta \mathrm{z}$ & $-0.59 \pm 0.67$ & $0.001^{*}$ \\
\hline \multirow[t]{6}{*}{ Ectocanine } & To the right side & $\Delta \mathrm{x}$ & $-2.12 \pm 0.89$ & $0.000^{*}$ \\
\hline & & $\Delta \mathrm{y}$ & $-0.58 \pm 0.90$ & $0.009^{*}$ \\
\hline & & $\Delta \mathrm{z}$ & $-0.45 \pm 0.54$ & $0.001^{*}$ \\
\hline & To the left side & $\Delta \mathrm{x}$ & $2.08 \pm 0.92$ & $0.000^{*}$ \\
\hline & & $\Delta \mathrm{y}$ & $-0.43 \pm 0.53$ & $0.002^{*}$ \\
\hline & & $\Delta \mathrm{z}$ & $-0.58 \pm 0.48$ & $0.000^{*}$ \\
\hline \multirow[t]{6}{*}{ Ectomolare } & Right & $\Delta \mathrm{x}$ & $-2.09 \pm 0.67$ & $0.000^{*}$ \\
\hline & & $\Delta \mathrm{y}$ & $-0.27 \pm 0.44$ & $0.013^{*}$ \\
\hline & & $\Delta \mathrm{z}$ & $-0.23 \pm 0.84$ & 0.228 \\
\hline & Left & $\Delta \mathrm{x}$ & $2.02 \pm 0.75$ & $0.000^{*}$ \\
\hline & & $\Delta \mathrm{y}$ & $-0.26 \pm 0.45$ & $0.020^{*}$ \\
\hline & & $\Delta \mathrm{z}$ & $-0.01 \pm 1.25$ & 0.987 \\
\hline \multirow[t]{6}{*}{ Processus zygomaticus } & Right & $\Delta \mathrm{x}$ & $-1.63 \pm 0.68$ & $0.000^{*}$ \\
\hline & & $\Delta \mathrm{y}$ & $-0.33 \pm 0.82$ & 0.091 \\
\hline & & $\Delta \mathrm{z}$ & $-0.19 \pm 0.35$ & $0.023^{*}$ \\
\hline & Left & $\Delta \mathrm{x}$ & $1.52 \pm 0.67$ & $0.000^{*}$ \\
\hline & & $\Delta \mathrm{y}$ & $-0.31 \pm 0.85$ & 0.119 \\
\hline & & $\Delta \mathrm{z}$ & $-0.22 \pm 0.36$ & $0.015^{*}$ \\
\hline
\end{tabular}

Paired $t$-tests were performed; *Statistical significance with $p<0.05$. 
Table 4. Lateral displacement of ANS, PNS, and alveolar bone width following expansion

\begin{tabular}{|c|c|c|c|c|c|c|c|}
\hline \multirow[b]{2}{*}{ Parameter } & \multicolumn{2}{|c|}{ Before } & \multicolumn{2}{|c|}{ After } & \multicolumn{2}{|c|}{ Difference } & \multirow[b]{2}{*}{$p$-value } \\
\hline & Mean (mm) & $\begin{array}{l}\text { Standard } \\
\text { deviation }\end{array}$ & Mean (mm) & $\begin{array}{l}\text { Standard } \\
\text { deviation }\end{array}$ & Mean $(\mathbf{m m})$ & $\begin{array}{l}\text { Standard } \\
\text { deviation }\end{array}$ & \\
\hline ANS width & 0.00 & 0.00 & 4.83 & 0.53 & 4.83 & 0.53 & $0.000^{*}$ \\
\hline PNS width & 0.00 & 0.00 & 3.95 & 0.50 & 3.95 & 0.50 & $0.000^{*}$ \\
\hline Alveolar bone width & 61.97 & 2.38 & 66.16 & 2.55 & 4.19 & 0.67 & $0.000^{*}$ \\
\hline
\end{tabular}

ANS, anterior nasal spine; PNS, posterior nasal spine.

Paired $t$-tests were performed; *Statistical significance with $p<0.05$.

Table 5. Pearson's correlation between the changes in soft tissue landmarks and the parameters used in the study

\begin{tabular}{|c|c|c|c|c|c|c|c|c|}
\hline \multicolumn{3}{|c|}{ Parameter } & \multicolumn{2}{|c|}{ ANS } & \multicolumn{2}{|l|}{ PNS } & \multicolumn{2}{|c|}{ Alveolar bone } \\
\hline Landmark & & Coordinate & $\begin{array}{c}\text { Pearson's } \\
\text { correlation }\end{array}$ & $p$-value & $\begin{array}{c}\text { Pearson's } \\
\text { correlation }\end{array}$ & $p$-value & $\begin{array}{c}\text { Pearson's } \\
\text { correlation }\end{array}$ & $p$-value \\
\hline Subnasale & & $\mathrm{z}$ & -0.422 & 0.064 & -0.423 & 0.063 & -0.209 & 0.376 \\
\hline \multirow[t]{4}{*}{ Cheek point } & Right & $\mathrm{x}$ & -0.912 & $0.000^{*}$ & -0.880 & $0.000^{*}$ & -0.304 & 0.192 \\
\hline & & $\mathrm{y}$ & -0.594 & $0.006^{*}$ & -0.576 & $0.008^{*}$ & -0.015 & 0.951 \\
\hline & Left & $\mathrm{x}$ & 0.976 & $0.000^{*}$ & 0.946 & $0.000^{*}$ & 0.308 & 0.187 \\
\hline & & $\mathrm{y}$ & -0.494 & $0.027^{*}$ & -0.494 & $0.027^{*}$ & -0.042 & 0.862 \\
\hline \multirow[t]{4}{*}{ Alar curvature point } & Right & $\mathrm{x}$ & -0.786 & $0.000^{*}$ & -0.780 & $0.000^{*}$ & -0.411 & 0.072 \\
\hline & & $\mathrm{y}$ & -0.487 & $0.029^{*}$ & -0.468 & $0.037^{*}$ & -0.138 & 0.563 \\
\hline & Left & $\mathrm{x}$ & 0.906 & $0.000^{*}$ & 0.883 & $0.000^{*}$ & 0.316 & 0.175 \\
\hline & & $\mathrm{y}$ & -0.559 & $0.010^{*}$ & -0.546 & $0.013^{*}$ & -0.115 & 0.515 \\
\hline
\end{tabular}

ANS, anterior nasal spine; PNS, posterior nasal spine; $\mathrm{x}, \mathrm{x}$-axis, the transverse axis; $\mathrm{y}, \mathrm{y}$-axis, the anteroposterior axis; $\mathrm{z}, \mathrm{z}$-axis, the vertical axis.

*Statistically significant at $p<0.05$.

affected $(p<0.01)$. Moreover, the changes in the $y$ coordinates of the cheek and alar curvature points on both sides were negatively affected by the separation at the ANS and PNS $(p<0.05)$.

Comparisons of the effects of ANS and PNS separation with the movements of the cheek and alar curvature points are shown in Table 6. Only the regression coefficients between movement in the $\mathrm{x}$-axis of the cheek points on both sides and the separation at ANS were statistically significant $(p<0.05)$. For these soft tissue points on both sides, the separation measured at the ANS had a stronger effect than that at the PNS.

The unstandardized coefficients produced by regression analysis, shown in Table 7, reflect the expected lateral movement of both cheek points depending on the separation at the ANS, and show high statistical significance $(p<0.001)$. Thus, they can be used to predict the lateral displacement of the cheek points from the split at the ANS by using the following regression equations:

Cheek point $R(x)$ change $=1.189-0.526 \times$ ANS separation

Cheek point $\mathrm{L}(\mathrm{x})$ change $=-1.385+0.510 \times$ ANS separation

\section{DISCUSSION}

Prediction of the possible changes in soft tissues caused by the hard tissue alterations after orthodontic treatment should precede treatment planning because the results have an important influence not only on macroesthetics such as the profile, vertical proportion, and nasal projection but also on microesthetics such as smile symmetry and incisor display. ${ }^{22}$ The increased use of MSEs in adult patients has raised concerns among clinicians regarding their impact on facial esthetics. However, only a limited number of studies have evaluated the effect of MSEs on the soft tissues of the midfacial region in adults. ${ }^{11,12}$

In this study, we used СВСТ to evaluate the midfacial soft tissue changes following MSE use and their correlation with the changes in hard tissues in young adults with transverse maxillary discrepancies. We used voxel-based registration, one of the six methods used to obtain a rigid registration, ${ }^{23}$ on the cranial base of preand post-expansion CBCT images to evaluate soft tissue 
Nguyen et al • Midfacial soft tissue change after MSE

Table 6. Regression coefficients between the changes in the cheek and alar curvature points on both sides and for ANS and PNS separation

\begin{tabular}{|c|c|c|c|c|c|}
\hline \multicolumn{3}{|c|}{ Variable } & \multirow{2}{*}{ Model } & \multirow{2}{*}{$\frac{\text { Standardized coefficients }}{\text { Beta }}$} & \multirow{2}{*}{$p$-value } \\
\hline Landmark & & Coordinate & & & \\
\hline \multirow[t]{8}{*}{ Cheek point } & Right & $\mathrm{x}$ & ANS & -0.862 & $0.028^{*}$ \\
\hline & & & PNS & -0.052 & 0.887 \\
\hline & & $\mathrm{y}$ & ANS & -0.535 & 0.457 \\
\hline & & & PNS & -0.061 & 0.932 \\
\hline & Left & $\mathrm{x}$ & ANS & 0.873 & $0.000^{*}$ \\
\hline & & & PNS & 0.107 & 0.574 \\
\hline & & $\mathrm{y}$ & ANS & -0.255 & 0.741 \\
\hline & & & PNS & -0.249 & 0.747 \\
\hline \multirow[t]{8}{*}{ Alar curvature point } & Right & $\mathrm{x}$ & ANS & -0.513 & 0.358 \\
\hline & & & PNS & -0.278 & 0.616 \\
\hline & & $\mathrm{y}$ & ANS & -0.484 & 0.535 \\
\hline & & & PNS & -0.003 & 0.997 \\
\hline & Left & $\mathrm{x}$ & ANS & 0.754 & 0.056 \\
\hline & & & PNS & 0.158 & 0.672 \\
\hline & & $\mathrm{y}$ & ANS & -0.451 & 0.542 \\
\hline & & & PNS & -0.113 & 0.878 \\
\hline
\end{tabular}

ANS, anterior nasal spine; PNS, posterior nasal spine; $\mathrm{x}, \mathrm{x}$-axis, the transverse axis; $\mathrm{y}, \mathrm{y}$-axis, the anteroposterior axis.

*Statistically significant at $p<0.05$.

Table 7. Regression coefficients between the changes in the cheek points on both sides and the separation at the ANS

\begin{tabular}{cccccccc}
\hline & Variable & & \multirow{2}{*}{ Model } & \multicolumn{2}{c}{ Unstandardized coefficients } & \multirow{2}{*}{$\boldsymbol{p}$-value } \\
\cline { 1 - 1 } Landmark & & Coordinate & & Beta & SE & \\
\hline Cheek point & Right & $\mathrm{x}$ & Constant & 1.189 & 0.272 & $0.000^{*}$ \\
& & & ANS & -0.526 & 0.056 & $0.000^{*}$ \\
& \multirow{2}{*}{ Left } & $\mathrm{x}$ & Constant & -1.385 & 0.129 & $0.000^{*}$ \\
& & & ANS & 0.510 & 0.027 & $0.000^{*}$ \\
\hline
\end{tabular}

ANS, anterior nasal spine; SE, standard error; $x$, $x$-axis, the transverse axis.

*Statistically significant at $p<0.05$.

displacement. A previous study indicated that CBCT can overcome the limitations of two-dimensional radiographs without exposing the patient to high levels of radiation, and allows the simultaneous evaluation of hard and soft tissues. ${ }^{24}$ Evaluations of soft tissue displacement using CBCT have become more common recently. ${ }^{14,25,26}$ While 3D stereophotogrammetry has been used to investigate the nasal soft tissue response to MSEs, it provides limited information about the underlying skeletal changes, and only the expansion amount was used for evaluation of transverse changes. ${ }^{12}$

Regarding soft tissue changes, we observed lateral and forward movements of the cheek points and the alar curvature points on both sides. These trends in soft tis- sue displacement in the lateral and forward directions and higher magnitudes around the cheek compared to the paranasal area after MSE use were similar to those observed in a previous study using 3D facial scanning. ${ }^{11}$ In the present study, the amount of lateral movement was greater than the forward movement, while the previous study primarily showed forward movement." Another study on MSEs that was performed using 3D stereophotogrammetry reported an increase of $1.214 \mathrm{~mm}$ in the alar base width after expansion by $7 \mathrm{~mm} .{ }^{12}$ This increase was lesser than that estimated from the sum of transverse movements of both alar curvature points $(2.05 \mathrm{~mm})$ observed in this study. Cheek projection was reported after surgically-assisted rapid palatal expansion 
(SARPE), and the amount (mean, $1.48 \mathrm{~mm}$ ) was greater than that observed in the present study. ${ }^{27}$ Magnusson et $\mathrm{al}^{28}$ reported an increase of $2.88 \mathrm{~mm}$ in alar base width after expansion by over $5 \mathrm{~mm}$ with SARPE, which was greater than that in the present study after expansion by $6.5 \mathrm{~mm}$. The reason for the limited skeletal changes after MSE use in comparison with those after SARPE is presumed to be that SARPE could reduce stress to separate the midpalatal suture. ${ }^{29}$ Torun $^{26}$ reported the cheek projection after RME as $1.6 \mathrm{~mm}$ in the prepubertal group, which was greater than that reported in the present study. Lateral movements of the alar base, soft tissues over the infraorbital foramen, and the soft tissue zygion were previously reported in growing patients after RME. ${ }^{14}$ This discrepancy might be attributable to the age variations among study samples and the factor of growth. Although this discrepancy cannot be easily explained, it might be attributed to differences in procedure techniques, analysis methods, and individual variations among patients.

The anterior and lateral movements of these soft tissue landmarks could be the result of the corresponding movement of the maxilla, which could be explained by the location of the maxillary rotational fulcrum. ${ }^{30}$ The maxilla is located medially and anteriorly relative to this fulcrum. Due to the outward rotation of the zygomaticomaxillary complex around the proximal part of the zygomatic process, each half of the maxilla will be displaced forward and laterally. ${ }^{30}$ Additionally, the asymmetrical lateral movement of the cheek and alar curvature points between the left and right sides presented in this study could be explained by the unequal movement of the two maxillary bones. Previous studies showed that the displacement of the anterior part of the maxillary bones could affect midfacial soft tissue during maxillary expansion $^{26}$ and might result in esthetic alterations in this region, which could become asymmetrical. ${ }^{20}$

In this study, a significant downward movement of the subnasale by $0.34 \mathrm{~mm}$ was observed, although the amount of displacement was small and less significant. Magnusson et al. ${ }^{28}$ reported significant inferior movement of the subnasale after SARPE, which is consistent with the result of this study. This could be explained by the median and inferior location of the maxilla relative to the fulcrum. Due to the outward rotation of the zygomaticomaxillary complex around the frontozygomatic suture area, the maxillary halves moved downward and outward. ${ }^{31}$

Concerning hard tissue changes, significant lateral movements were observed for all evaluated hard tissue landmarks, including significant forward displacements of the A point, prosthion, and ectocanine and a significant downward shift of the A point following MSE use. These types of movements are consistent with the findings of previous studies. ${ }^{30,31}$ The data obtained in this study showed that the midpalatal suture was successfully split in all patients after MSE use. The mean separation at the PNS was about $81.78 \%$ of that at the ANS. This ratio demonstrates that the MSE created an almost parallel split of the midpalatal suture, in agreement with the findings of previous studies. ${ }^{17,20}$ The amount of separation at the midpalatal suture produced by the MSE in this study $(4.94 \mathrm{~mm}$ at the ANS and 4.01 $\mathrm{mm}$ at the PNS) was nearly equivalent to that in the study by Cantarella et $\mathrm{al}^{20}(4.8 \mathrm{~mm}$ and $4.3 \mathrm{~mm}$ at the ANS and PNS, respectively). In comparison with the traditional RPE, expansion by an MSE produced a much greater suture opening, with reference to the findings reported by $\mathrm{Oh}$ et al. ${ }^{17}$ using a tooth-anchored maxilla expander $(2.97 \mathrm{~mm}$ and $2.26 \mathrm{~mm}$ at the ANS and PNS, respectively). The reason could be related to the mechanism of action of MSEs. This appliance is located in the posterior portion of the hard palate, with four bicortical miniscrews positioned medial to the zygomatic buttress, allowing the opening force to be distributed along the entire suture length. ${ }^{20}$ As a result, while tooth-borne maxillary expanders (Hyrax-type expander, RME) created a V-shaped expansion pattern of the maxillary palatal suture, MSEs could produce an almost parallel split at the midpalatal suture. ${ }^{21}$ The amount of expansion by the appliance $(6.5 \mathrm{~mm}$; range, $5.2-8.0 \mathrm{~mm}$ ) was calculated on the basis of the patients' statements and was greater than the increase in the ANS/PNS. This could imply errors in counting the number of turns of the appliance. Moreover, the possibility of deformation of the appliance can be expected.

In Pearson's correlation analysis, the lateral and forward movements of the cheek and alar curvature points on both sides correlated with the amount of suture opening at the ANS and PNS after MSE use. The correlation between the lateral changes on both sides of the cheek and the alar curvature points and hard tissue changes was greater than that seen for the forward changes in soft tissue landmarks and skeletal movements.

The regression coefficients derived from these correlations were used to investigate the extent to which the separations at the ANS and PNS affect the changes in soft tissue landmarks. The ANS split had a greater effect than the PNS split on the cheek and alar curvature points in the $x$ - and $y$-axes. This could be attributed to the fact that the ANS is anatomically closer to the cheek and alar curvature points than the PNS. Additionally, the only statistically significant regression coefficients were seen between the lateral movement of the cheek points on both sides and the separation at the ANS. The effect of MSEs on soft tissues has rarely been studied using $\mathrm{CBCT}$, and to our knowledge, this is the first study 
to evaluate the 3D changes in midfacial soft tissues and the correlation of soft tissue changes with underlying skeletal alterations after MSE in young adults. The results suggested that limited changes in cheek point width were observed up to a certain amount of ANS separation $(2.26 \mathrm{~mm}$ on the right side and $2.71 \mathrm{~mm}$ on the left side), while they would be increased beyond that point. The sum of the average amount of lateral displacement of both cheek points was $2.43 \mathrm{~mm}$, which is $57.9 \%$ of the underlying transverse alveolar expansion and $37.38 \%$ of appliance expansion in this study. These findings indicate that clinicians should be aware of the possibility of this change.

Considering the age of the included patients (mean, 22.4 years; range, 17.6-27.1 years) in this study and the short period between T0 and T1, the influence of confounding factors such as potential growth and possible weight differences between samples could be considered to be minimal. Since the soft tissue changes could be affected not only by the extent and direction of the skeletal movement but also by multifactorial components such as the tonicity of the surrounding muscle and tissue thickness, skin elasticity, facial type, and weight change, different results from the same treatment might be demonstrated among individual patients. Thus, it is conceivable that some patients would show improvement, while others would show deterioration. ${ }^{32}$ Nevertheless, this study could be useful for clinicians to provide information for predicting the soft tissue changes related to MSE usage. The results of this study imply that MSEs would be beneficial in young adult patients with a narrow face, midfacial deficiency, and paranasal depression without additional maxillary surgery. ${ }^{32}$ However, this study had limitations, such as a relatively small sample size and short follow-up period. Further prospective studies using CBCT with larger sample sizes are required to evaluate the long-term stability of these changes. Even though the spatial resolution of CBCT scans was reported to be $0.22-0.23 \mathrm{~mm},{ }^{33}$ the results should be interpreted with caution since a considerable number of values in the tables were smaller than the spatial resolution. ${ }^{34}$

\section{CONCLUSION}

The midfacial soft tissue landmarks, specifically the cheek and alar curvature points on both sides, were displaced in the forward and lateral directions following MSE use. Opening of the maxillary palatal suture observed at the ANS and PNS correlated with the lateral and forward movements of the cheek and alar curvature points on both sides. The correlation between the lateral changes in soft and hard tissue was higher compared to the forward changes. Two regression equations predict- ing the forward movement of the two cheek points were established.

\section{CONFLICTS OF INTEREST}

No potential conflict of interest relevant to this article was reported.

\section{REFERENCES}

1. McNamara JA. Maxillary transverse deficiency. Am J Orthod Dentofacial Orthop 2000;117:567-70.

2. Cross DL, McDonald JP. Effect of rapid maxillary expansion on skeletal, dental, and nasal structures: a postero-anterior cephalometric study. Eur J Orthod 2000;22:519-28.

3. Haas AJ. Palatal expansion: just the beginning of dentofacial orthopedics. Am J Orthod 1970;57:21955.

4. Adkins MD, Nanda RS, Currier GF. Arch perimeter changes on rapid palatal expansion. Am J Orthod Dentofacial Orthop 1990;97:194-9.

5. Geran RG, McNamara JA Jr, Baccetti T, Franchi L, Shapiro LM. A prospective long-term study on the effects of rapid maxillary expansion in the early mixed dentition. Am J Orthod Dentofacial Orthop 2006;129:631-40.

6. Gurel HG, Memili B, Erkan M, Sukurica Y. Longterm effects of rapid maxillary expansion followed by fixed appliances. Angle Orthod 2010;80:5-9.

7. MacGinnis M, Chu H, Youssef G, Wu KW, Machado AW, Moon W. The effects of micro-implant assisted rapid palatal expansion (MARPE) on the nasomaxillary complex--a finite element method (FEM) analysis. Prog Orthod 2014;15:52.

8. Lagravère MO, Carey J, Heo G, Toogood RW, Major PW. Transverse, vertical, and anteroposterior changes from bone-anchored maxillary expansion vs traditional rapid maxillary expansion: a randomized clinical trial. Am J Orthod Dentofacial Orthop 2010;137:304.e1-12; discussion 304-5.

9. Lee KJ, Park YC, Park JY, Hwang WS. Miniscrew-assisted nonsurgical palatal expansion before orthognathic surgery for a patient with severe mandibular prognathism. Am J Orthod Dentofacial Orthop 2010;137:830-9.

10. Carlson C, Sung J, McComb RW, Machado AW, Moon W. Microimplant-assisted rapid palatal expansion appliance to orthopedically correct transverse maxillary deficiency in an adult. Am J Orthod Dentofacial Orthop 2016;149:716-28.

11. Abedini S, Elkenawy I, Kim E, Moon W. Three-dimensional soft tissue analysis of the face following micro-implant-supported maxillary skeletal expan- 
sion. Prog Orthod 2018;19:46.

12. Lee SR, Lee JW, Chung DH, Lee SM. Short-term impact of microimplant-assisted rapid palatal expansion on the nasal soft tissues in adults: a threedimensional stereophotogrammetry study. Korean J Orthod 2020;50:75-85.

13. Staderini E, Patini R, De Luca M, Gallenzi P. Threedimensional stereophotogrammetric analysis of nasolabial soft tissue effects of rapid maxillary expansion: a systematic review of clinical trials. Acta Otorhinolaryngol ltal 2018;38:399-408.

14. Kim KB, Adams D, Araújo EA, Behrents RG. Evaluation of immediate soft tissue changes after rapid maxillary expansion. Dental Press J Orthod 2012;17:157-64.

15. Moss JP. The use of three-dimensional imaging in orthodontics. Eur J Orthod 2006;28:416-25.

16. Vanarsdall RL Jr. Transverse dimension and longterm stability. Semin Orthod 1999;5:171-80.

17. Oh H, Park J, Lagravere-Vich MO. Comparison of traditional RPE with two types of micro-implant assisted RPE: CBCT study. Semin Orthod 2019;25:608.

18. Cevidanes LH, Heymann G, Cornelis MA, DeClerck $\mathrm{HJ}$, Tulloch JF. Superimposition of 3-dimensional cone-beam computed tomography models of growing patients. Am J Orthod Dentofacial Orthop 2009;136:94-9.

19. Bazina M, Cevidanes L, Ruellas A, Valiathan M, Quereshy F, Syed A, et al. Precision and reliability of Dolphin 3-dimensional voxel-based superimposition. Am J Orthod Dentofacial Orthop 2018;153:599606.

20. Cantarella D, Dominguez-Mompell R, Mallya SM, Moschik C, Pan HC, Miller J, et al. Changes in the midpalatal and pterygopalatine sutures induced by micro-implant-supported skeletal expander, analyzed with a novel 3D method based on CBCT imaging. Prog Orthod 2017;18:34.

21. Lim HM, Park YC, Lee KJ, Kim KH, Choi YJ. Stability of dental, alveolar, and skeletal changes after miniscrew-assisted rapid palatal expansion. Korean J Orthod 2017;47:313-22.

22. Sarver DM. Interactions of hard tissues, soft tissues, and growth over time, and their impact on orthodontic diagnosis and treatment planning. Am J Orthod Dentofacial Orthop 2015;148:380-6.

23. Cevidanes LH, Motta A, Proffit WR, Ackerman JL, Styner M. Cranial base superimposition for 3-dimensional evaluation of soft-tissue changes. Am J Orthod Dentofacial Orthop 2010;137(4 Suppl):S120-9.

24. Nur RB, Çakan DG, Arun T. Evaluation of facial hard and soft tissue asymmetry using cone-beam computed tomography. Am J Orthod Dentofacial Orthop
2016;149:225-37.

25. Lee TY, Kim KH, Yu HS, Kim KD, Jung YS, Baik HS. Correlation analysis of three-dimensional changes of hard and soft tissues in class 111 orthognathic surgery patients using cone-beam computed tomography. J Craniofac Surg 2014;25:1530-40.

26. Torun GS. Soft tissue changes in the orofacial region after rapid maxillary expansion: a cone beam computed tomography study. J Orofac Orthop 2017;78:193-200.

27. Nada RM, van Loon B, Maal TJ, Bergé SJ, Mostafa YA, Kuijpers-Jagtman AM, et al. Three-dimensional evaluation of soft tissue changes in the orofacial region after tooth-borne and bone-borne surgically assisted rapid maxillary expansion. Clin Oral Investig 2013;17:2017-24.

28. Magnusson A, Bjerklin K, Kim H, Nilsson P, Marcusson $A$. Three-dimensional computed tomographic analysis of changes to the external features of the nose after surgically assisted rapid maxillary expansion and orthodontic treatment: a prospective longitudinal study. Am J Orthod Dentofacial Orthop 2013;144:404-13.

29. Lima SM Jr, de Moraes M, Asprino L. Photoelastic analysis of stress distribution of surgically assisted rapid maxillary expansion with and without separation of the pterygomaxillary suture. J Oral Maxillofac Surg 2011;69:1771-5.

30. Cantarella D, Dominguez-Mompell R, Moschik C, Sfogliano L, Elkenawy 1, Pan HC, et al. Zygomaticomaxillary modifications in the horizontal plane induced by micro-implant-supported skeletal expander, analyzed with СВCT images. Prog Orthod 2018;19:41.

31. Cantarella D, Dominguez-Mompell R, Moschik C, Mallya SM, Pan HC, Alkahtani MR, et al. Midfacial changes in the coronal plane induced by microimplant-supported skeletal expander, studied with cone-beam computed tomography images. Am J Orthod Dentofacial Orthop 2018;154:337-45.

32. Pangrazio-Kulbersh V, Wine P, Haughey M, Pajtas B, Kaczynski R. Cone beam computed tomography evaluation of changes in the naso-maxillary complex associated with two types of maxillary expanders. Angle Orthod 2012;82:448-57.

33. Abouei E, Lee S, Ford NL. Quantitative performance characterization of image quality and radiation dose for a CS 9300 dental cone beam computed tomography machine. J Med Imaging (Bellingham) 2015;2:044002.

34. Molen AD. Considerations in the use of cone-beam computed tomography for buccal bone measurements. Am J Orthod Dentofacial Orthop 2010;137(4 Suppl):S130-5. 